\title{
Tracheal bronchus: an unusual cause of difficult ventilation
}

\author{
Divya Jain, MD • Neerja Bhardwaj, MD • Ashish Pareek, MD • Badal Parikh, MD
}

Received: 27 April 2017/Revised: 1 June 2017/Accepted: 16 June 2017/Published online: 22 June 2017

(C) Canadian Anesthesiologists' Society 2017

We recently experienced a "cannot ventilate scenario" in a child caused by entrapment of an endotracheal tube (ETT) in a tracheal bronchus.

This four-month-old American Society of Anesthesiologists physical status I infant, weighing $5 \mathrm{~kg}$, presented with a stoma prolapse and was scheduled for stoma closure. She had undergone previous operations under general anesthesia to address her anorectal malformation and had been previously successfully intubated and ventilated via a 3.5-mm ETT. Following intravenous induction and neuromuscular blockade, bag-and-mask ventilation was achieved. On laryngoscopy, a Cormack Lehane grade 1 glottic view was obtained, and we attempted to advance a 4-mm uncuffed ETT into the trachea. However, resistance was experienced when the ETT was just below the glottis. As the glottis had been crossed, we attempted to ventilate the lungs via the ETT but were unable. On suspicion of subglottic stenosis, endotracheal intubation using a smaller ETT was attempted but similarly failed. Owing to the non-emergent nature of the surgery, the infant was awakened to allow investigation of suspected tracheal stenosis.

The following day, the child underwent helical computed tomography (CT) bronchoscopy using helical datasets from the base of the skull to $\mathrm{T} 4$ on a 64-detector scanner (Terrarecon workstation; Aquillion 64, Toshiba America Medical Systems, Tochigi, Japan). The CT scan revealed the presence of an accessory (i.e., tracheal) bronchus arising from the right posterolateral wall of the

D. Jain, MD $(\bowtie) \cdot$ N. Bhardwaj, MD · A. Pareek, MD

B. Parikh, MD

Department of Anesthesia and Intensive Care, Post Graduate Institute of Medical Education and Research, Chandigarh, India

e-mail: jaindivya77@ rediffmail.com trachea (Figure). We suspected that the distal end of the ETT abutting on the tracheal bronchus resulted in the inability to ventilate and resistance to advancing the ETT. The child was subsequently successfully anesthetized and intubated using a 4-mm ETT that was advanced with its tip rotated at $180^{\circ}$ to avoid being diverted into the accessory bronchus. A flexible bronchoscope had been prepared to facilitate ETT passage had our initial attempt been unsuccessful.

A tracheal bronchus is an anatomical variation wherein an accessory bronchus originates from the trachea usually $<2 \mathrm{~cm}$ above the carina and commonly from the right lateral wall of the trachea. It has an incidence of

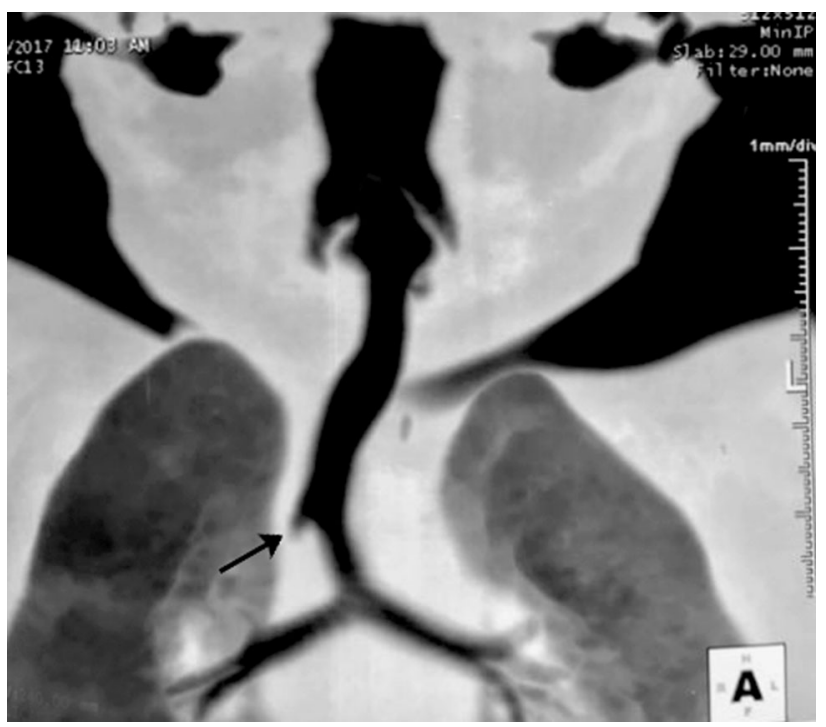

Figure Computed tomography shows a typical presentation of the tracheal bronchus (arrow) originating from the right posterolateral position approximately $2 \mathrm{~cm}$ above the carina. 
$0.1-3.0 \% .^{1,2}$ This condition generally remains undiagnosed because of its relative lack of symptoms. However, there have been reports of hypoxemia, atelectasis, ${ }^{3}$ and difficulty placing double-lumen tubes due to the presence of the tracheal bronchus. ${ }^{4}$ Preoperative diagnosis of a tracheal bronchus might be possible by reviewing the chest radiograph and in doing so aid in a successful airway management plan.

Conflicts of interest None declared.

Editorial responsibility This submission was handled by Dr. Hilary P. Grocott, Editor-in-Chief, Canadian Journal of Anesthesia.

Ethics Not applicable.

Funding None.

\section{References}

1. Shih FC, Lee WJ, Lin HJ. Tracheal bronchus. CMAJ 2009; 180: 783.

2. Harris JH Jr. Clinical significance of tracheal bronchus. AJR Am J Roentgenol 1983; 141: 623.

3. Vredevoe LA, Brechner T, Moy P. Obstruction of anomalous tracheal bronchus with endotracheal intubation. Anesthesiology 1981; 55: 581-2.

4. Moon YJ, Kim SH, Park SW, Lee YM. The implications of a tracheal bronchus on one-lung ventilation and fibreoptic bronchoscopy in a patient undergoing thoracic surgery: a case report. Can J Anesth 2015; 62: 399-402. 